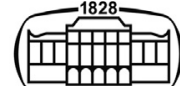

AKADÉMIAI KIADÓ

UNIVERSITY of DEBRECEN

\section{International Review of Applied Sciences and Engineering}

13 (2022) 1, 11-21

DO1:

$10.1556 / 1848.2021 .00224$

(C) 2021 The Author(s)

\section{ORIGINAL RESEARCH} PAPER

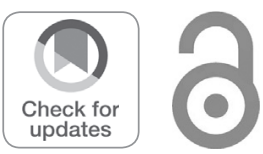

\section{Cells and building structures. Part II. The loadbearing units in cells of the building - The cells in the loadbearing elements of the building}

\author{
Géza Lámer* ${ }^{*}$ \\ Department of Engineering Management and Enterprise, Faculty of Engineering, University of \\ Debrecen, Ótemető u. 2-4, H-4028, Debrecen, Hungary
}

Received: December 15, 2020 • Accepted: June 9, 2021

Published online: August 26, 2021

\section{ABSTRACT}

In this study, the relationship between the structure of the supporting frame and cells is addressed.

The possible arrangements of the four primary structural elements - foundation, walls and pillars, slabs, roof - in global form as well as in a single cell are looked at. The types of connections of each support member to the support elements below are examined. In line with this, the layout and possible structure of the foundation, and the possible layout of walls and pillars as well as slab is reviewed. The main possibilities for structural design of the roof structure are outlined.

Using the concepts of cells, and arrangement and division of cells there is given some applications. The different building types that can be interpreted using arrangement of cells as well as some applications are shown.

\section{KEYWORDS}

cell as building structure, structure of surface-like building constructions, supporting frames of buildings, arrangement of cells and buildings

\section{INTRODUCTION}

Building materials (finished products), as well as space-forming and load-bearing building structures, in particular foundations, walls and pillars, ceilings and roof structures, have been interpreted as distinctive geometric shapes, point-like, line-like and surface-like structures [1, 2]. In a building, each space is a three-dimensional cell, the building structures (walls and slabs) that delimit the space as a cell boundary are two-dimensional cells, while the building structures (beams, pillars, columns) that delimit them are one-dimensional cell boundaries. As the final step of the procedure, the point-like building structures (pillar head and foot, structural nodes) were interpreted as the boundary of a one-dimensional cell (and a zerodimensional cell at the same time) $[1,2]$.

The study is based on the building structures, supporting structures and the boundary structures in particular. The various structures interpreted in the context of building structures are described according to various aspects in the literature. For instance, Davies and Jokiniemi [3] review the relationship between form, structure and function. Siegel [4] reviews the modern forms of loadbearing structures. Gilyén [5] examines the load-bearing capacity of the support structure depending on the material and the shape of the building material used. Onouye and Kane [6] review the statics and strength of loadbearing building structures and suggest the possibility of describing the representation of the frames, the trusses and the pillar frame with the help of cells. Bajza [7] groups the description of building structures based on building technology. For long-span spatial overlays, specific structural drawings show a close relationship with the cells.

The supporting structures of buildings can be described in a set of different aspects. Sandaker, Eggen and Cruveller review various support structures (e.g., horizontal and 
vertical, kinematically definite and indefinite) in one- and two-dimensional support structure pairs (beam and plate, rope and tarpaulin) [8]. The relationship between architecture, space and order for each supporting structure is reviewed by Ching [9]. The concept of order in this approach is closely related to the cellular interpretation of structures. A similar approach is used to design structures by Ching, Onouye, and Zubnerbuhler [10].

In this paper, the emphasis is on the cellular structure. For each supporting structure (foundations, walls and pillars, slab and roofs), specific examples of the various structures and ways of joining are given. It is shown that the 12 building types (see [11]) interpreted by the supporting frame can be "reinterpreted" by means of cells and operations within cells. It is also shown how with the help of operations by cells it is possible to create a space with a larger scale space than cells in the supporting frame.

\section{STRUCTURES OF LOADBEARING CONSTRUCTION}

In this section, the loadbearing constructions of the building: foundations, walls and pillars, slabs and roof structures are reviewed (see for example $[8,9,10]$ ). In the review, the emphasis is on the presentation of the cellular structure.

\subsection{Structures of foundation}

Viewed from the above, the foundation can have different layouts, i.e., it can have different structures: the arrangement can be point-like, line-like, surface-like or surface arrangement. The linear arrangement may be longitudinal or transverse (see Fig. 1).

Flat foundations include block and cup bases (as a system of point-like foundations) (Fig. 1a), bar- and beamfoundations (as line-like foundations) (Fig. 1b), beam grid foundation (as bidirectional line-like foundations or "quasisurface" foundation) (Fig. 1c), and finally the plate and shell foundations (as surface arrangement foundations) (Fig. 1d).

Deep foundations include foundations using piles, wells, cabinets and slab walls (i.e., box foundation). In the floor plan, piles and wells can be placed in points, either individually or in groups (Fig. 1a). Piles (in sparse and dense configurations) or slurry walls can be placed in a line-like arrangement (Fig. 1b). In the case of piles or wells there are examples of "beam grid foundation" arrangement (Fig. 1c), but not in the case of slurry walls. The caisson foundation follows the overall dimensions of the building. Depending on whether or not the load distribution plate is prepared, a surface or line arrangement is typical.

Some footings of point-like foundations (see Fig. 1a) may receive the pillars/walls independently, but each base body may be joined by a beam (Fig. 1b), beam grid (Fig. 1c) or plate (Fig. 1d). That is, the structural distribution is precisely reflected in Fig. 1: while in the case of continuously constructed foundations, Fig. 1a-d shows the foundation structure itself, Fig. 1a-d reflects the structures of the "head structure" that joins the point-like bodies in the case of point-like foundation.

\subsection{Structures of walls and/or pillars}

The layout of walls and pillars in the floor plan may be the same as or different from the layout of the foundation plan. In the first case, Fig. 1 also shows the layout of the walls and pillars: longitudinal or cross-walled frame (Fig. 1b), cellular layout wall structure (Fig. 1c), pillar frames (Fig. 1a), finally, the simultaneous application of walls and pillars leads to mixed frames.

If the two layouts are different, there is some kind of load-distributing structure, usually a beam, support grid or plate, between the foundation and the vertical load-bearing structural elements.

The vertical support structure can be a wall only, a wall and a pillar at the same time, or only a pillar.

The floor plan arrangement is usually characterized by the nodes of a network. A good example of this is Fig. 1.

\subsection{Slab structures}

The floor plan and division of the slab can be:

- cell-adapted,

- crossing a cell in one or two directions.

The structure of the slab can be within a cell: - in one unit: flat or structured plate (slab)

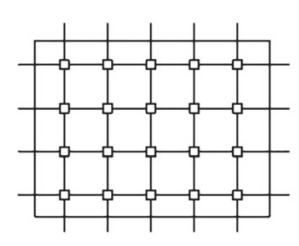

a) Point-like arrangement

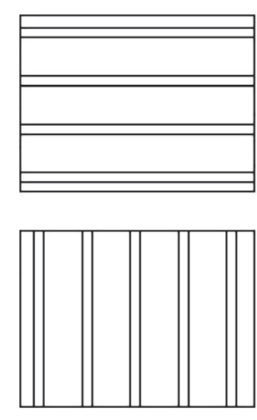

b) Line-like arrangement
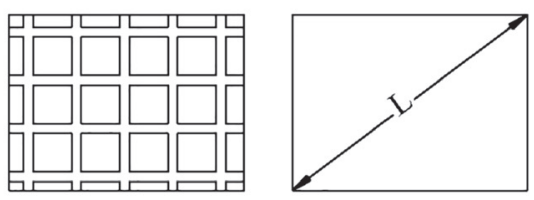

c) Surface-like arrangement d) Surface arrangement

Fig. 1. Structural allocation of foundations viewed from above 
- beam slab (parallel allocation of the identical beams),

- main and drawer beam system,

- beam grid system slab.

Slabs sit directly on the walls or pillars. Accordingly, the arrangement of the slab is determined by the arrangement of the walls and the pillars, respectively.

The base structure of the slab is shown in Fig. 2. In the case of a "sliced" unidirectional load-bearing slab, walls or beams are required at both ends of the preferred direction to support the slab (Fig. 2a). In the case of a "monolithic" twoway load-bearing slab, walls or beams are required on all four sides to support the slab; or it may be sufficient to support the slab with one pillar at each of the four corners (Fig. 2b).

\subsection{Roof and covering structures, relationship with the ascending structure}

The layout and division of the roof can be as follows:

- adapted to the enclosing load-bearing structure,

- adapted to the load-bearing cell system,

- crossing over a cell in one or two directions.

The diversity of roof profiles is well known. Convex forms are used to show the relationship with the cells. Note. As a result of the static action, for some bar, shell, cable and tarpaulin structures, the roof surface can only be concave. The base of the roof structure is chosen as a rectangle, an octagon, and a circle, almost imitating that the polygons approach the circle. In this section, the semicircle from the beam supported on each other, through a polygonal line is got to.

The main types of (convex) roof structures are summarized in Fig. 3.

The base of the roof structure in each column is the same. In each column, the floor plan of the roof is two parallel sections, square, octagon, and circle, respectively. This is shown in the first line. Note. By implication, it could be fitted 16, 32, etc. angles between the octagon and the circle. According to the floor plan, the roof structures in the first column end in an edge (ridge) at the highest points of the roof, the roof structures end at the apex in the second, third and fourth columns at the highest point of the roof.

In the first three columns, the roof surfaces are shaped as system of planes. In the fourth column, the roof surface is shaped as a curved surface.

The first row (viewed from below) shows the floor plan of the roofs.

In the second row, one plane per side is used between the roof lower edges and the roof ridge/apex. These roof structures include the gable roof, the tent roof, the octagonal pyramid roof and the cone roof.

In the third row, two planes per side are used between the roof lower edges and the roof ridge/apex. These lead to the mansard-type roofs.

In the fourth row, three planes per side are used between the roof lower edges and the roof ridge/apex. These lead to various plate works such as the polygonal cylindrical surface as well as the polygonal domes and the twice broken cone surface.
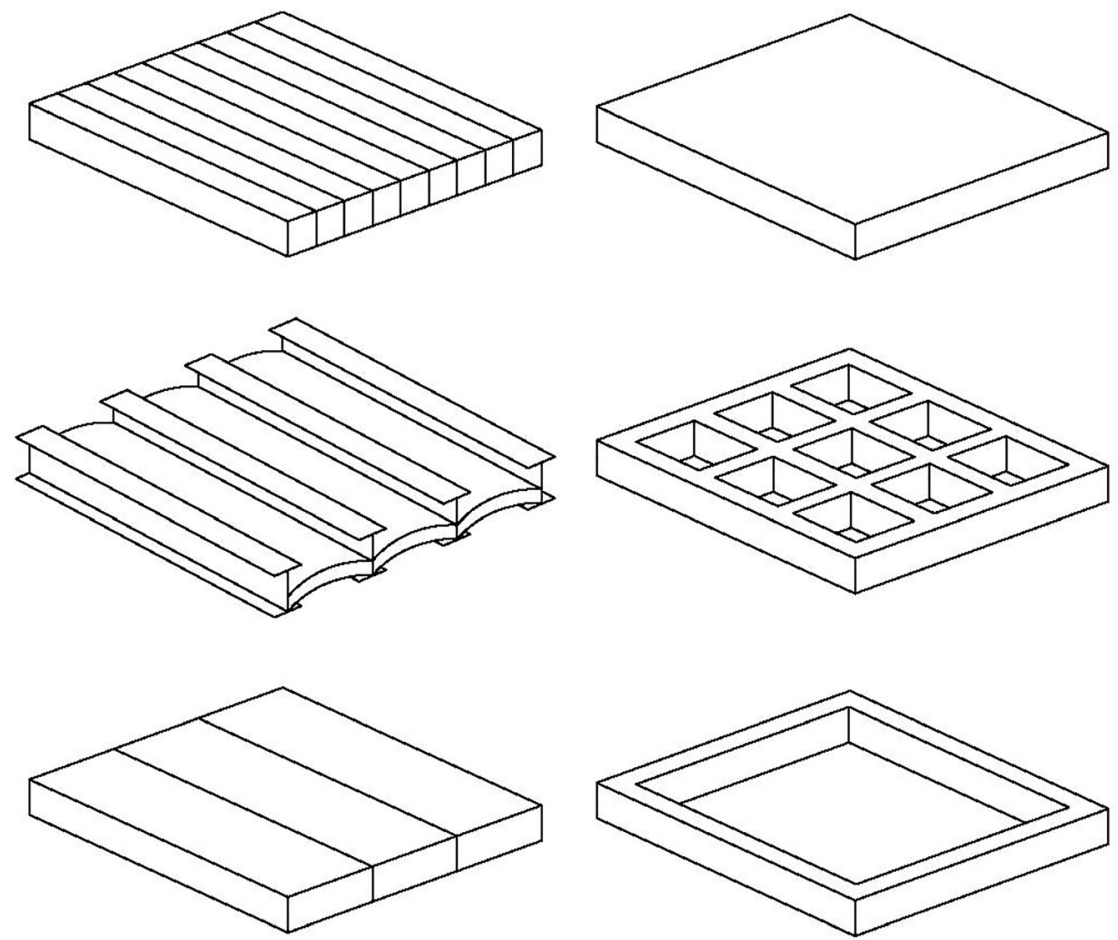

a) One-way slabs

(supported by two parallel walls or girders)

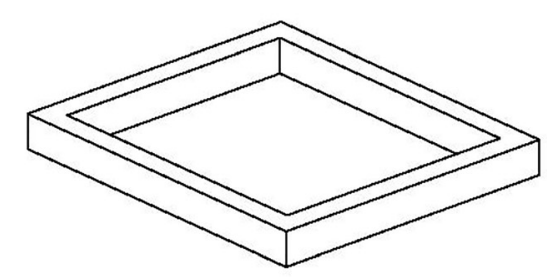

b) Two-way slabs

(supported on all sides by walls or pillars on four corners)

Fig. 2. One- and two-way slabs 

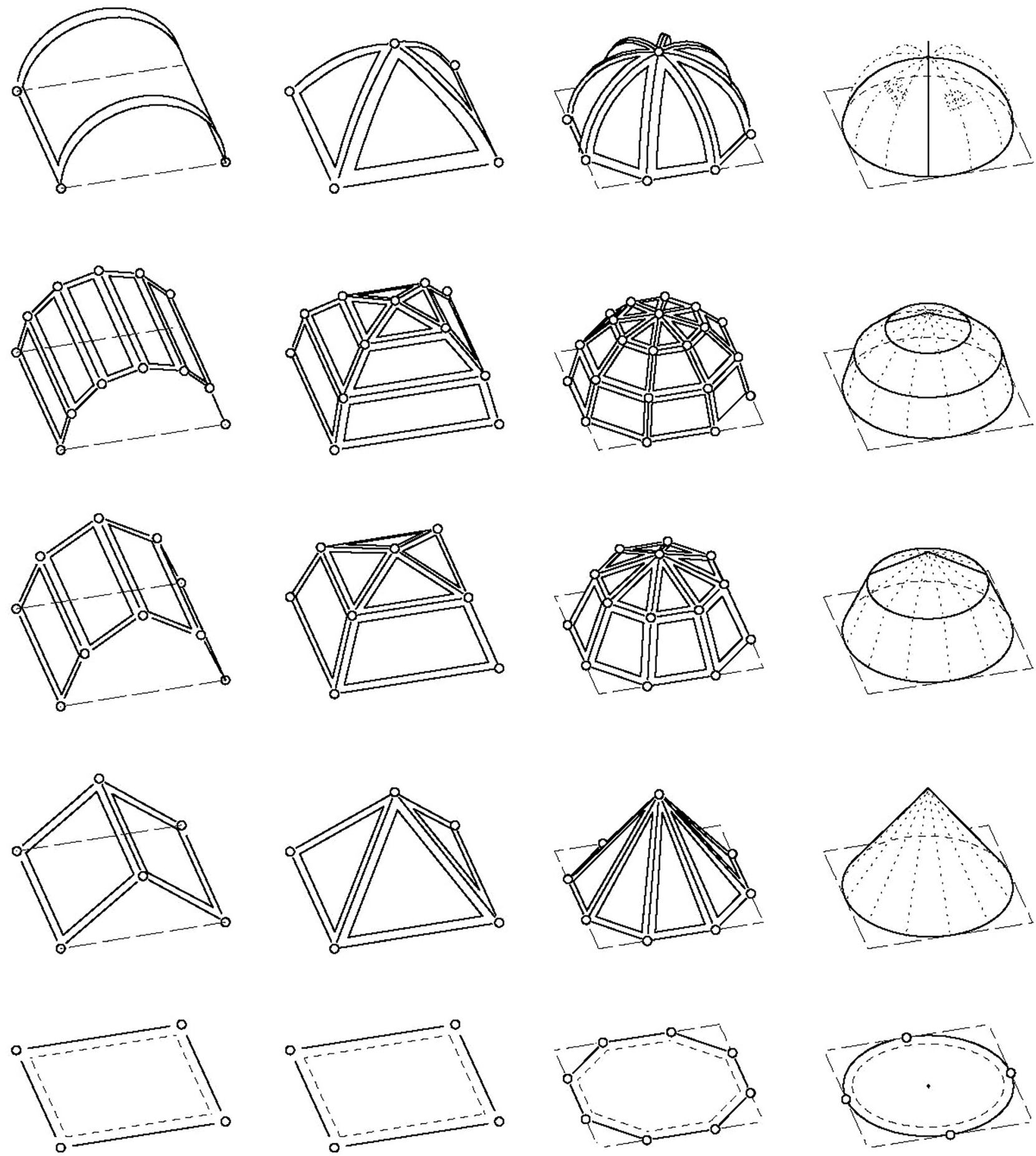

Fig. 3. Structures of the roof and the cells

In the fifth row, a smooth (fracture-free in the horizontal direction) surface is applied side by side between the roof lower edges and the roof ridge/apex. These lead to a cylindrical surface, a rectangular and octagonal monastery vault, and a hemispherical or rotating surface vault. The surfaces thus obtained (see the middle two figures in the fifth row in Fig. 3) are generally not smooth in the vertical direction, but are interspersed with edges (ribs).
Note. Implicitly, among the three planes and the surfaces without breakpoints, the surfaces obtained by using four, five, etc. planes could be also examined.

In addition to the convex shape, the concave shape can also be examined. Here, the gable surface is mentioned as the most common concave shape in roofing.

The structures of the roof surface are formally identical to the structures of the surface structure. 
The connection of the roof structure to the walls and/or pillars basically depends on whether the floor plan of the vertical support structure and the roof structure is either the same or not. Similarly to the foundation, in the case of sameness, the direct connection is typical, in the case of a different arrangement, an intermediate load-distributing structure is required. In the present case, the latter can also be a beam, a support grid or a plate.

\section{GENERAL APPLICATIONS: ARRANGEMENT OF CELLS AND TYPES OF BUILDINGS}

\subsection{Type of buildings}

The building types were designed based on the supporting frame (see [11]). The classification of the building based on the supporting frame is as follows:

- A masonry wall and pillar-framed building with a vaulted ceiling and a roof covering

- Masonry wall and pillar frame building with flat (!) slab (The (!) Sign refers to the Prussian vault slab, which, although a vaulted slab, is classified as a flat one.)

- Monolithic reinforced concrete wall frame building

- Prefabricated reinforced concrete block-panel building

- Pillar frame building made of prefabricated reinforced concrete elements

- Pillared building with monolithic slab
- A building with a pillar frame formed as a spatial frame

- Mixed-frame buildings

- Rod (truss and frame) structures

- Cable structures

- Shells and plate works (including a folding plate systems)

- Tarpaulin and tent structures

The present study does not discuss masonry walled buildings with vaulted slabs or mixed-framed buildings. The relationship between the other building types and the classification of cells is described below.

\subsection{Wall-framed buildings}

In wall frame buildings, the wall and slab are arranged (see Fig. 4).

Masonry walled building with a flat (!) slab (Fig. 4a). The wall frame is continuous: in the (generally) parallel planes of the load-bearing walls, cells are built continuously next to and above each other. This is made possible by mortar bonding technology. The horizontal surface elements of the cells - the slabs - are built between the main walls. The connection is "articulated" in the case of a retracted wall design, as the slab basically rests on the walls, or on the "shoulder" formed in the wall. The connection is partial clamping in the case of beams implanted in the nest, masonry, clamped in a wreath, or in the case of monolithic reinforced concrete slabs. This partial clamping in the slab allows for a moment rearrangement, the moment in the wall is not "rearranged".

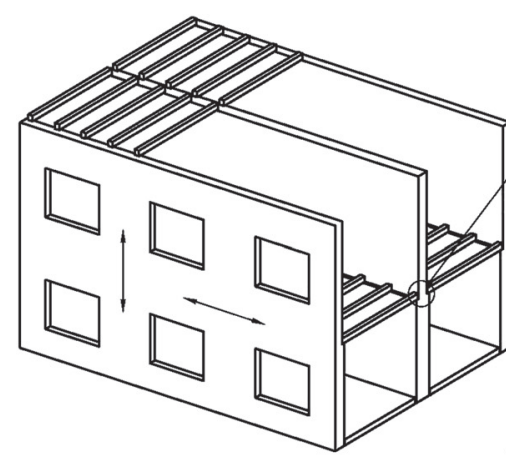

a) Masonry wall-framed building: continuous walls, intermittent slabs

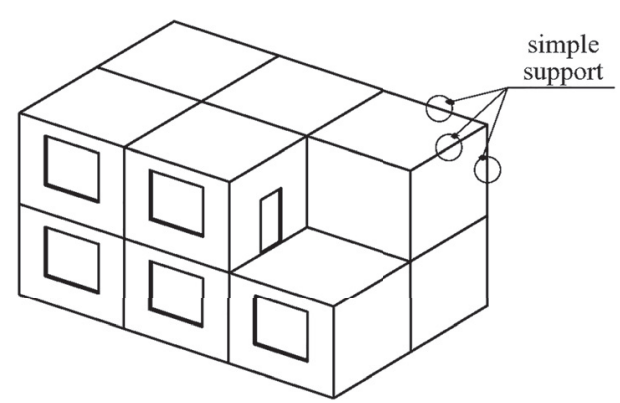

c) Panel building: continuous walls and slabs per cell unit

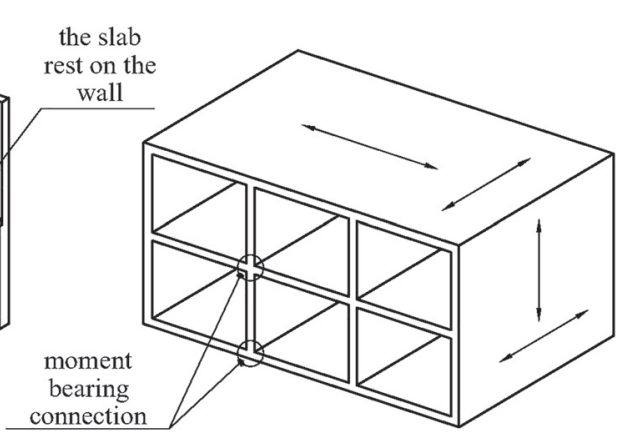

b) Monolithic reinforced concrete wall-framed building: continuous walls and continuous slabs

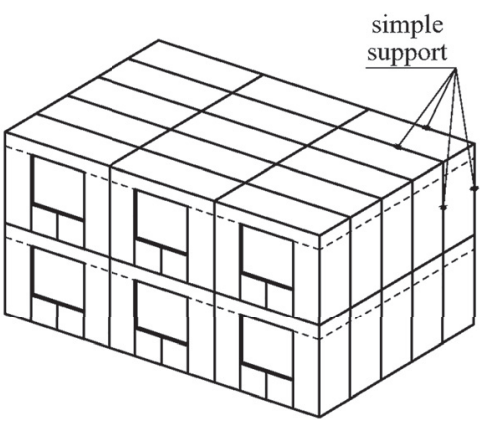

d) Block building: band-like walls and slabs per cell unit

Fig. 4. Connection of cells in a wall-framed building 
Monolithic reinforced concrete walled building (Fig. 4b). The walls and slab, as elements of the frame, are continuous: due to the concrete technology, the wall and slab are continuous and form moment-resistant structure, and the moments "migrate" from the slab to the wall and vice versa. This type of building can be considered as a special plate work.

Block-panel building (Fig. $4 \mathrm{c}$ and $4 \mathrm{~d}$ ). Both the wall blocks and the wall panels as well as the floorboards and the floor panels are placed next to each other. The connection is made by fixing the reinforcing steels together (hooking, screwing, welding) and concreting the working gap. The connection is suitable for partial moment transmission. In the first approximation, the connections can be considered as jointed, there is no moment transmission between slab and wall, for more accurate calculations it should be considered as a partially captured structure. Because blocks and panels create a closed cell (rectangular cuboid), the system can be considered as a cell. In this case, the six sides of the brick provide sufficient rigidity even if the blocks and panels are simple jointed along the edges.

\subsection{Pillar-framed buildings}

In pillar-framed buildings, pillars and slabs are sorted (see Fig. 5).
Pillar frame building made of prefabricated reinforced concrete elements. Both the pillars and the girders are one cell long each. (Occasionally, the pillar can be two or three cells high.) Their connection is considered to be a partially moment-resistant structure, jointed in the first approximation, and partially captured for more accurate calculations. The slab is located directly on the beams, their connection is jointed. The horizontal "disc effect" is created by the upper structural unit of the slabs, the monolithic concrete layer. The unit of the building is shown in Fig. 5b.

Pillar frame with monolithic slab. Both the pillars and the monolithic slabs are continuous in themselves, the connection between the two can be jointed and can also be moment-bearing. (The former is typical for steel columns and reinforced concrete slabs, the latter for monolithic reinforced concrete pillars and slabs.) At each level, the cells are not physically separated, the pillar frame marks the location of future cells (see Fig. 5a).

A building with a pillar frame formed as a spatial frame. The pillars are continuous relative to the beams that create each level, each of the beams running in two directions are continuous relative to both the other row of beams and the columns (see Fig. 5c). The three main support members are moment-connected to each other and do not have a joint.

Note. All three types of buildings use a separate stiffening structure, usually stiffening walls, stiffening cores, or

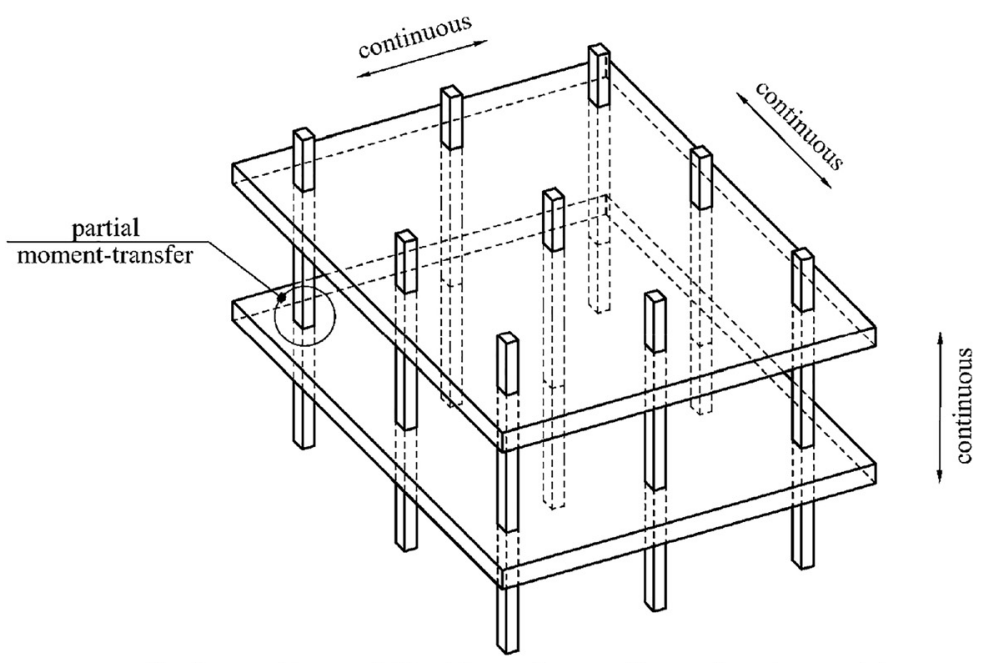

a) Pillar frame with monolithic slab: continuous pillars and continuous slabs

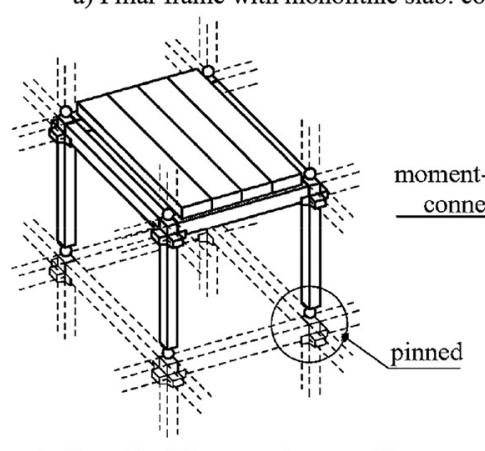

b) Mounted pillared building: continuous pillars, beams and slabs per cell unit

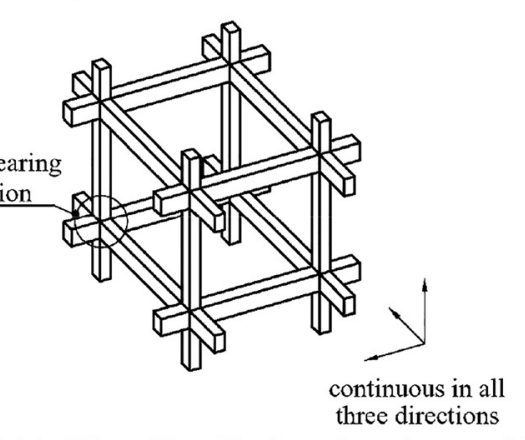

c) A building with a pillar frame formed as a spatial frame: continuous pillars and beams

Fig. 5. Connection of cells in a pillar-framed building 
stiffening lattice elements ("rows" and "columns" of "St. Andrew's crosses"). Mounted partition wall is the typical internal boundary.

\subsection{Building frames without walls and pillars}

Types of buildings without walls and pillars ("neither-nor"): rod (truss and frame) structures, rigid surface structures (as disk, plate and shell), cable structures and tarpaulin (and tent) structures.

In a cell basically there is a frame, a cable support structure as a "beam", a shell and a tarpaulin structure. The types of buildings obtained by displacement and/or rotation from this are usually single-storey. The elements that make up the building are shown in Fig. 6, and the buildings themselves are shown in Figs 7-10.

Hall building by displacing (sorting) the frame structure: spatial coverage requires purlins or purlin rings on the edge. The rigidity is provided by the stiffening "St. Andrew's crosses" between the frame structures, i.e., the wind beams (see Fig. 7).

Hall building by displacing (sorting) cable support structure as a "frame": spatial coverage requires secondary cable supports perpendicular to the main cable support structure as a "beam" and annular lanyards relative to the radial cable head supports (their role is functionally the same as that of the elements). The rigidity of the system is ensured by lanyards securing the columns at an angle. These are functionally identical to the wind beams between the frame structures (see Fig. 8).

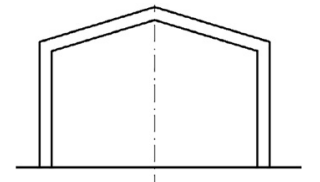

a) Rod structure (truss and frame)

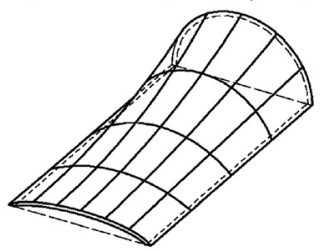

c) Shell (and plate work) structure

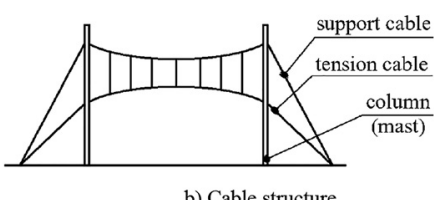

b) Cable structure

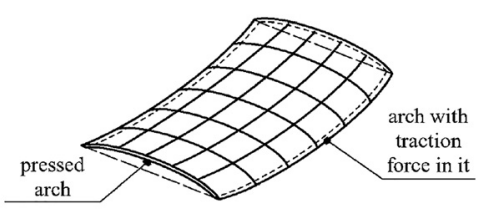

b) Tarpaulin and tent structure
Fig. 6. Elements of "neither-nor" building frame

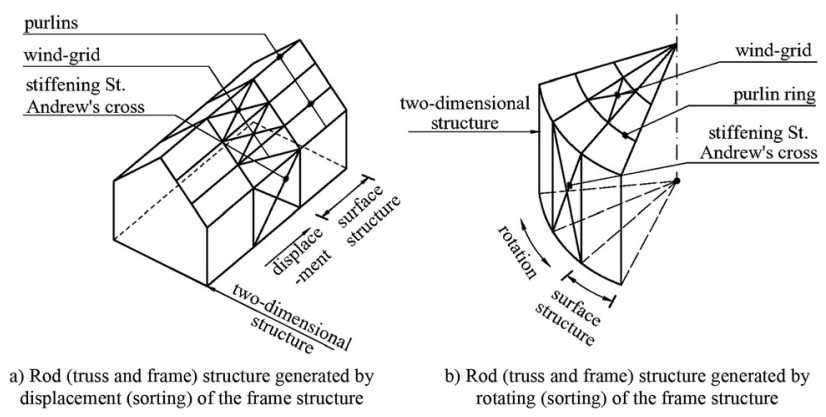

Fig. 7. Components of rod structure building frame

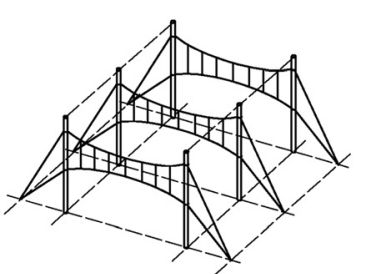

a) Cable structure generated by displacement

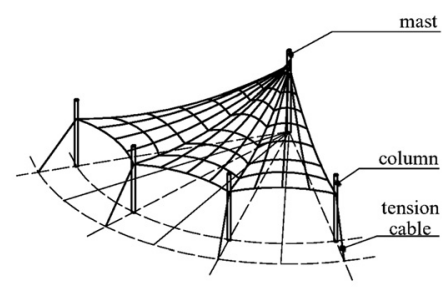

b) Cable structure generated by rotation
Fig. 8. Components of cable structured building frame

Single-storey by displacing (sorting) shell structure: the spatial coverage is provided by the shell structures arranged one after the other. Rigidity is given by the surface structure itself (see Fig. 9).

Single-storey building by displacing (sorting) the tarpaulin structure: the spatial coverage is provided by the canopy structures arranged one after the other. Rigidity is given by the multi-directional tension of the tarpaulin structures (see Fig. 10).

The structural units are provided in the figures, which are listed. For each structural unit (rod, cable, shell, tarpaulin), two modes of generation (displacement and rotation) were given. Mapping purlins and stiffening wind beams and St. Andrew's crosses are indicated. In the case of a cable structure, the surface formed of the cables is not flat, therefore a wind beam and a St. Andrew's cross cannot be used; the tension cable makes an angle with the planes of the cable support structure as a "beam" in the spatial design. The figures show the surface units formed from the line structures: beam and pillar, as well as cable; in the case of shells and tarpaulins, the surface units are not structured but homogeneous.

Remarks. In the case of line structures, different names for different mechanical behaviour: truss and frame, together the term rod structure are used. In the case of surface

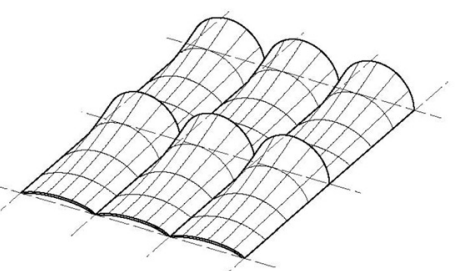

a) Shell structure generated by displacement

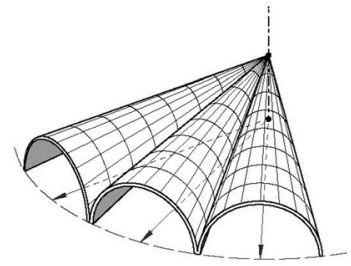

b) Shell structure generated by rotation
Fig. 9. Components of shell structured building frame
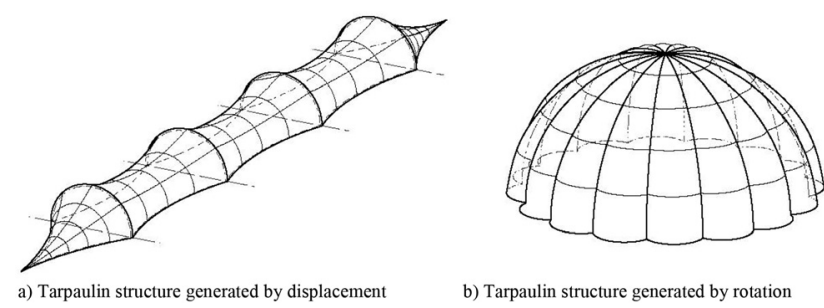

Fig. 10. Components of tarpaulin structure building frame 
structures, different names for different mechanical behaviour: disk, plate and shell, together the term rigid surface structure are used.

Additions. The rigid surface structure is usually thought to be not only continuous but also smooth. However, a surface structure is not necessarily smooth: its individual parts may fit together with edges. Examples of planar boundary surfaces are the middle six images of Fig. 3 , in the case of a curved surface, see the middle two images of the last column of Fig. 3 when the images are conceived as a reinforced concrete structure, and Fig. 9. Rigid surface structures composed of flat surface structures that fit together along edges are also commonly referred to as either plate work (system) [10] or folded structures [12]. The elementary classification of forms of folded structures is given by Šekularac [13]. Three types are distinguished by [13]: folded plate, folded frames and spatial folded plate structures.

The basic idea of folding is to fold a flat sheet along parallel edges. In architecture, it is preferred to use a folded "plate" with a zigzag or a trapezoidal line curve (Fig. 11) usually used as a special kind of flat roof or structured wall (see [14]). The cells are the strips.

Two-layer folding leads to folded surfaces consisting of rhombus fields. Fig. 12 shows a typical fold for a different network. It shows the typical folds for different networks that can be interpreted in the plane. Cells are elements of the network, or rhombuses (and triangles). In Fig. 12a and 12b, each element of the fold is an oblique rhombus, while in the case of Fig. $12 \mathrm{c}$ and $12 \mathrm{~d}$, the element of the fold is an oblique rhombus and a horizontal element of the network, as well as inclined triangles.

Of course, a folded surface can also be formed from oneand two-way curved surfaces (see Fig. 13). These variants are simple analogy of variants of folding plates, which are shown in Fig. 11.

Two-layer folding of one- and two-way curved surfaces leads to the building frames without walls and pillars with continuous but not smooth surface structure. On Fig. 14, two examples are shown.

Some other examples are given in [12, 13, 15-17].

\section{MISCELLANEOUS APPLICATIONS}

\subsection{Generalized cell and arranged (generalized) cells side by side}

By building side-by-side generalized cells composed of individual line elements, i.e., frames and different rope a) square

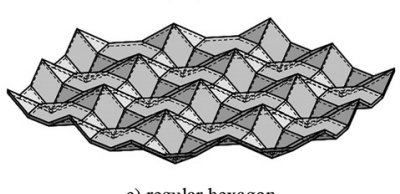

c) regular hexagon

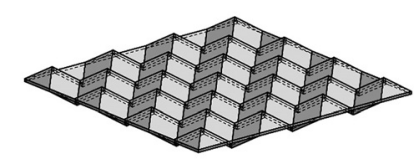

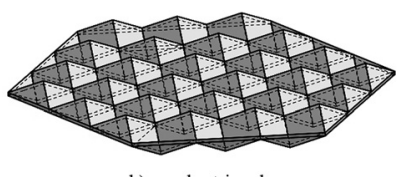

b) regular triangle

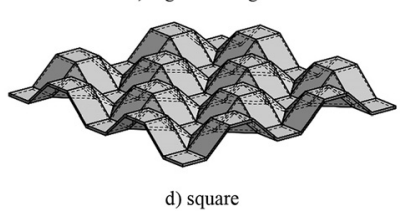

Fig. 12. Plates folded from rhombuses and triangles (and network elements) with different network

structures, and generalized cells composed of individual surface elements, i.e., shell and tarpaulin structures, stand-alone buildings can be constructed (see Figs 7$10)$.

\subsection{Division of the surface onto cells: structuring the surface structure by designing the material}

In the following, the case of the slab is considered. Slabs are usually rectangular surface structures marked with walls (or pillars). The structures of the possible division of the rectangular surfaces are shown in Fig. 15 below. During the division, keeping in mind that the slab is not composed of lines, but of structural elements. Accordingly, the structural elements of the divisions - main and drawer beams, beam grid - correspond to the divisions.

The surface - see surface $L_{0}$ - can be covered with pointlike, line-like and surface-like elements. The brick vault is covering with point-like elements. The dense beam wood floor is covering with line-like elements. Reinforced concrete slab is covering with surface-like elements.

The surface constructions - slab and disc - can be made as a structure of constant thickness. It is an unstructured structure. Dividing the surface into smaller surfaces uses line-like elements to structure the surface constructions. The structural height of each structural element is different. Accordingly, division and different structural heights can be used to transform an unstructured structure into a structured construction. To do this, the surface structure is divided into parts and the material is formed (shaped) as if it had a beam, a main beam, but in fact, as a unit, the surface construction is made of the same material. This is made possible by two building materials: reinforced concrete and steel. In any case, it can be said that reinforced concrete and steel provide an opportunity for the beams used in the division and the plate made above (or below

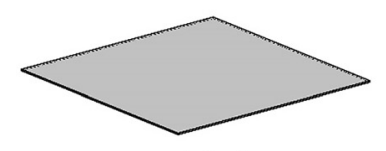

a) straight line

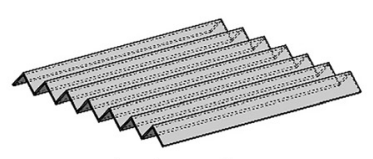

b) zigzag line

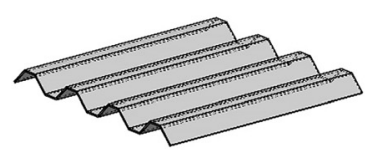

c) trapezoidal line

Fig. 11. Plates folded from strips with different directrix 


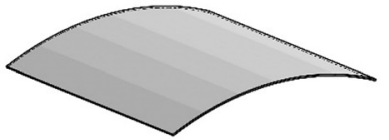

a) right circular cylinder folded along generatrix of cylinder

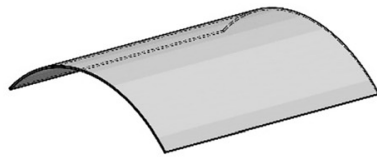

d) right circular cylinder folded along directrix of cylinder

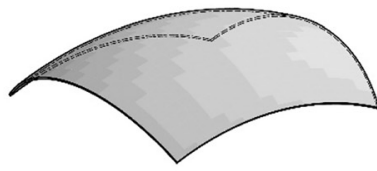

g) sphere folded along circle segment

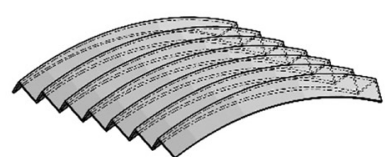

b) zigzag line

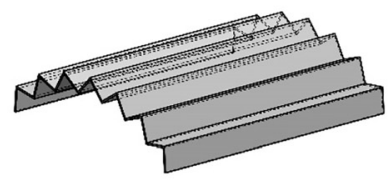

e) zigzag line

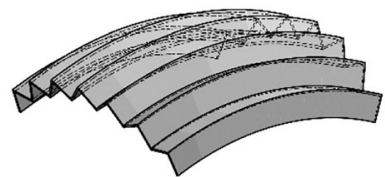

h) zigzag line

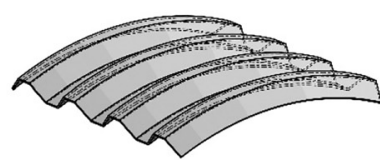

c) trapezoidal line

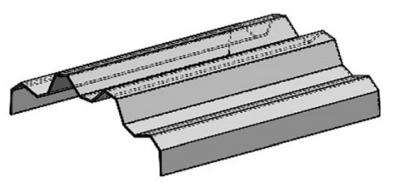

f) trapezoidal line

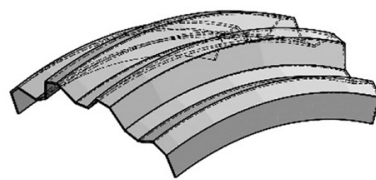

i) trapezoidal line

Fig. 13. Different folded surface from curved strip with different directrix and generatrix

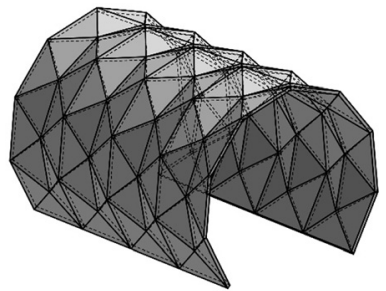

a) circular cylinder with horizontal axis

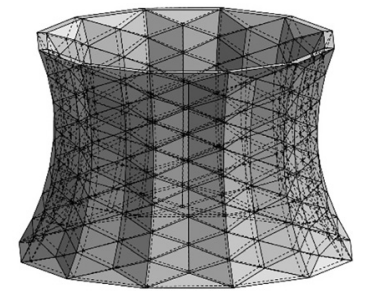

b) hyperbolic paraboloid with vertical axis
Fig. 14. Folded surface from rhombus as building frames without walls and pillars

them) to work together. Note. The goal is precisely for the material present in the structure to participate in the static action on both the scale between the walls and between the dividing beams.

In the case of reinforced concrete, the four beam divisions - no dividing beams, one-way dividing beams, main- and drawer beam, beam grid - can be made of four types of plates: flat plate (Fig. 16a), bottom (top) ribbed plate (Fig. 16b), bottom (top) ribbed plate with stiffening ribs (Fig. 16c), plate cooperating with beam grid (Fig. 16d).

\subsection{Merge cells: creating space greater than space of one cell}

In the case of a masonry walled building, the cell can be joined by leaving the walls to create a larger space, at the same time the height of the floor beams must be increased, in the case of a cellular joint covering the whole building, not with a beam, but covering the space with a lattice girder (see Fig. 17).

In the case of a column-framed building, the cell can be merged by leaving the pillars to create a larger space, at the same time the master beams and pillars must be merged into a multi-storey high frame (see Fig. 18). In Fig. 18, the diagonal section with arrows at both ends indicates the merged space, while the pillars and master beams represented by a solid line form the merged structure, i.e., the multi-storey frame.

\subsection{Merge cells: due to size of building increases, the force distribution changes in the building}

In the case of a block, as well as panel building, the horizontal load is disregarded, as it follows from the structural design of the building that it absorbs the stresses caused by the wind load. In the case of skyscraper, hundreds of meters high three-dimensional framed buildings act as a bar of complex cross-section (merged cell) clamped at one end

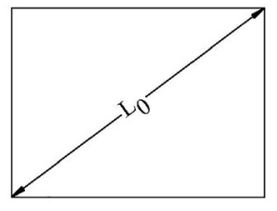

a) One surface

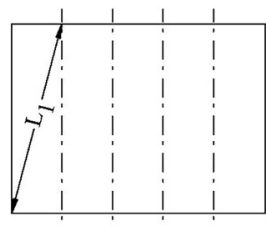

b) Division into bands with beams

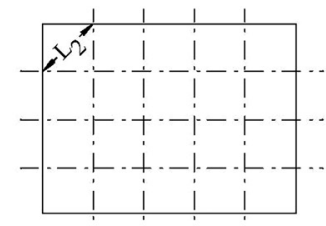

c) Division into rectangles with mainand drawer beams

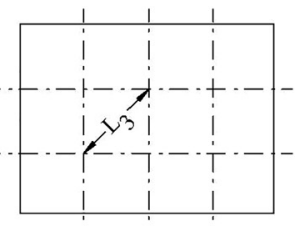

d) Division into rectangle with beam grid

Fig. 15. Division of surface into smaller surfaces 


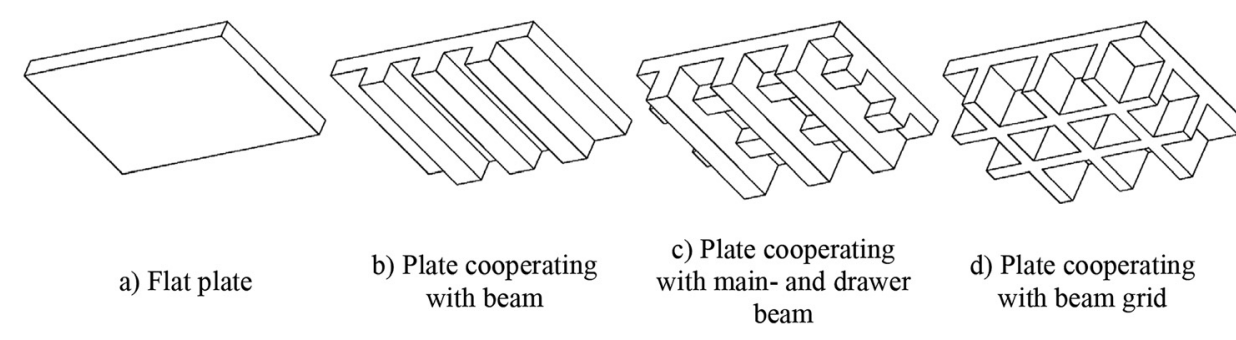

Fig. 16. Designs of single layer structured plate

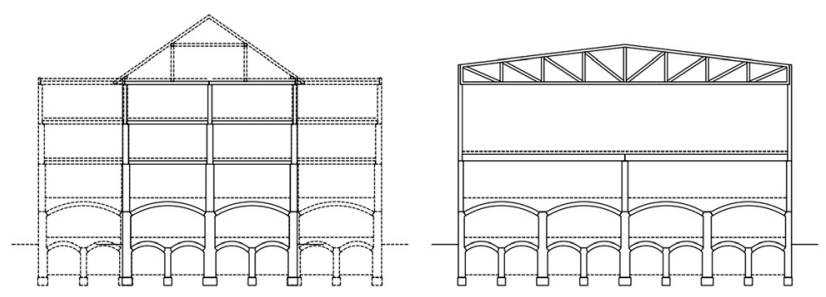

Fig. 17. Merge cells: masonry walled building
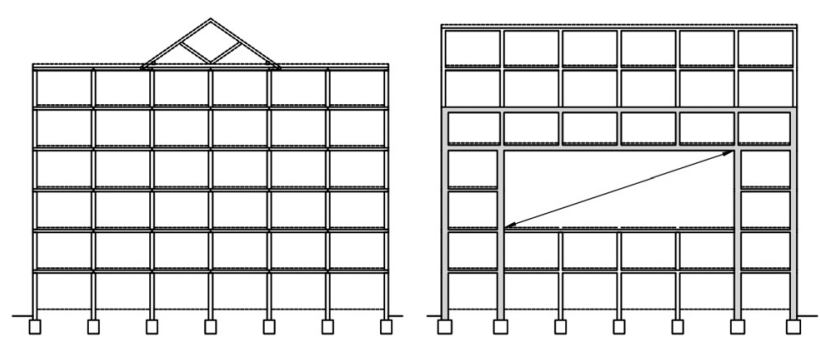

Fig. 18. Merge cells: column-framed building under the effect of horizontal loading. The proportions and the main elements of the structural design of skyscraper as well as block building are shown in Fig. 19.

\subsection{A recommendation to further development of research topic in other different relations between building's cells and building's systems}

In the following topics, the description of the relationship between cells and building structures can be further developed:

- space shaping building structures and cells,

- the totality (as sum) two-part of the line-like and surfacelike structures of the building as a spatial support structure with a cellular structure,

- the analogy between folded and cellular structures,

- refinement of the previously introduced 12-element building type system based on the cell layout and the mechanical connection of the cell elements (simple jointed and moment-bearing)
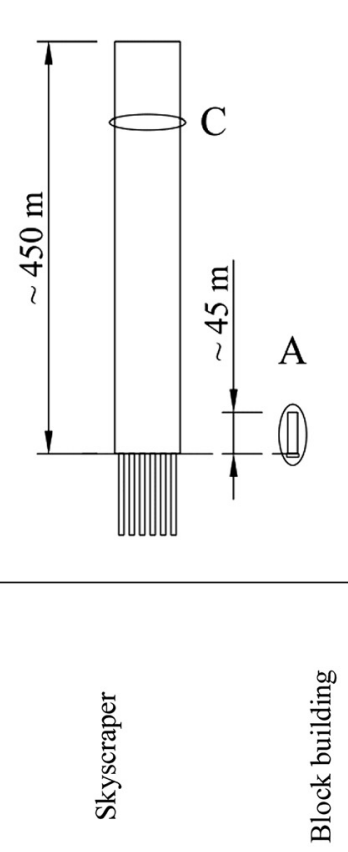

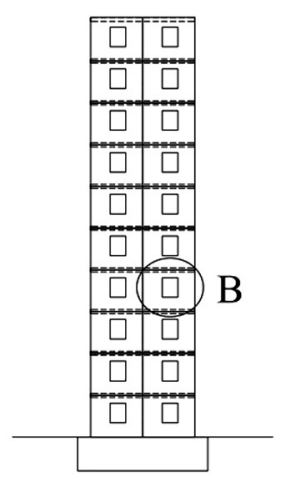

A) vertical section of block building

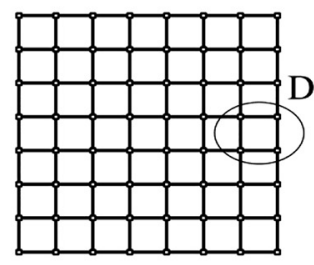

C) horizontal section of a skyscraper

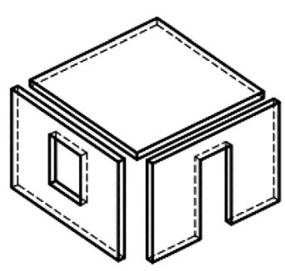

B) cell unit in a block building

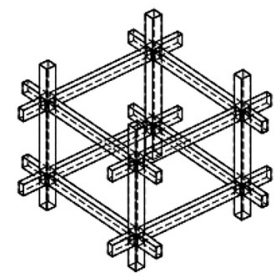

D) cell unit in a skyscraper

Fig. 19. Merge cells: change in scale 


\section{SUMMARY}

In the two-part study, a new approach - the use of cells - to examine the supporting structures and spatial boundary systems of a building is proposed. Cell modelling is used on two scales to describe the supporting structures and space delimitation systems of a building. One scale is the building as a whole, in which model the basic unit of cell description is the three-dimensional cell enclosed (designated) by four walls (or four pillars) and two slabs, the walls and slabs delimiting it as two-dimensional cells. (This series of models are continued with pillars and beams that can be interpreted as boundaries of planar cells, with point-like building structures delimiting them.) The other scale is the level of building structures, when the structured construction is considered as a set of cells. At both scales, the four main structural elements (foundations, walls/pillars, slab, and roof) are reviewed and showed the different possibilities of analogies with cells on the one hand, and the possibility of interpreting different arrangements on the other hand.

The supporting frame of the building can be walls, pillars, or in their absence, bar, cable, shell and tarpaulin structures. The way of sorting of cells can be primarily displacement and displacement along the arc (i.e., rotation). In the case of wall frames, each building type is determined by the construction technology of the wall - masonry wall, monolithic reinforced concrete, prefabricated reinforced concrete panel, or block. In the case of a pillar frame, the construction technology also determines the type of building with a pillar frame: it can be a pillar frame consisting of prefabricated elements, a pillar frame with a monolithic slab, and a three-dimensional frame. The four types of building without pillars and walls are given by the structure of bars, cables, shells and tarpaulins.

In the building type without wall and pillar, special attention was paid to the folded structures. One of the (most common) approaches to folded structures is the origami. In the present study, the folded structures as a continuous but not smooth surface structure based on cellular modelling was (re)interpreted. Folded surface structures are interpreted as a set of two-dimensional cells consisting of rhombuses (as well as polygons of the basic network and triangles) that fit into the base surface network. Although the surface structures thus obtained are continuous on the cylindrical surfaces raised on the base mesh, they are not smooth but "held with edges".

It was shown that the 12 building types interpreted by the supporting frame can be "reinterpreted" by means of cells and operations within cells. It was also shown how, with the help of operations with cells, a space with a larger scale space than cells in the supporting frame can be created.

\section{LITERATURE}

[1] G. Lámer, "Modelling the structure of the loadbearing structure using cells," in Müszaki Tudomány az Észak-kelet Magyarországi régióban. Szolnok, 2018. május hó 31. Konferencia kiadványa. Szerk.: Bodzás Sándor. Debrecen: Debreceni Akadémiai Bizottság Műszaki Szakbizottsága, 2018, pp. 140-58. (In Hungarian).

[2] G. Lámer, "Cells and building structures: Part I. Cells - point-like, line-like and surface-like bodies - building structures," Int. Rev. Appl. Sci. Eng., vol. 11, no. 2, pp. 123-34, 2020. https://doi.org/10. 1556/1848.2020.20011.

[3] N. Davies, and E. Jokiniemi, Dictionary of Architecture and Building Construction. Amsterdam - Boston - Heidelberg: Elsevier, 2008. https://doi.org/10.4324/9780080878744.

[4] C. Siegel, Strukturformen der modernen Architektur. München: Verlag Georg D. W. Callwey, 1960.

[5] N. Gilyén, Structure and Form in the Architecture. Budapest: Müszaki Könyvkiadó, 1982, (In Hungarian).

[6] B. Onouye, and K. Kane, Statics and Strength of Materials for Architecture and Building Construction. 4th ed., Boston: Prentice Hall, 2012.

[7] J. Bajza, Building and its Structure. Budapest: Technical Foundation of Architecture. TERC, 2015, (In Hungarian).

[8] B.N. Sandaker, A.P. Eggen, and M.R. Cruvellier, The Structural Basis of Architecture. 3rd ed. Routledge, Taylor \& Francis Group, 2019, p. 560.

[9] F.D.K. Ching, Architecture: Form, Space, and Order. 3rd ed., John Wiley \& Sons, Inc., 2007.

[10] F.D.K. Ching, B. Onouye, and D. Zubnerbuhler, Building Structures Illustrated. Patterns, Systems, and Design. $2^{\text {nd }}$ ed., John Wiley \& Sons, Inc., 2014.

[11] G. Lámer, "Building constructions and structures. Part I. Classification of buildings according to framework," Int. Rev. Appl. Sci. Eng., vol. 7, no. 1, pp. 29-43, 2016. https://doi.org/10.1556/1848.2016.7.1.5.

[12] T. Shen, and Y. Nagai, "An overview of folding techniques in architecture design,” World J. Eng. Technol., vol. 5, pp. 12-9, 2017. https://doi.org/10.4236/wjet.2017.53B002.

[13] N. Šekularac, J.I. Šekularac, and J. Š. Tovarović, "Folded structures in modern architecture," Facta Universitatis. Series: Architecture Civil Eng., vol. 10, no. 1, pp. 1-16, 2012. https://doi.org/10.2298/FUACE1201001S.

[14] L. Kollár, Ed. Design of Engineering Constructions and Structures. Budapest: Akadémiai Kiadó, 2000. (In Hungarian).

[15] Frostickp, B. Arch, and M. Arch, "Antiprism based form possibilities for folded surface structures," Architectural Sci. Rev., vol. 21, no. 3, pp. 59-67. https://doi.org/10.1080/00038628.1978.9696403.

[16] M. Stavric, and A. Wiltsche, "Quadrilateral patterns for rigid folding structures,” Int. J. Architectural Comput., vol. 12, no. 1, pp. 61-79.

[17] S.E.M. Calretas, and M.S.M. Kong, "Architecture and paper structures - could paper-folding become a methodology in architecture?," Appl. Mech. Mater., vols 548-549, pp. 1627-34, 2014. https://doi.org/10.4028/www.scientific.net/AMM.548-549.1627.

Open Access. This is an open-access article distributed under the terms of the Creative Commons Attribution 4.0 International License (https://creativecommons.org/ licenses/by/4.0/), which permits unrestricted use, distribution, and reproduction in any medium, provided the original author and source are credited, a link to the CC License is provided, and changes - if any - are indicated. (SID_1) 